\title{
RESPONSABILIDADES PELO CUIDADO DO IDOSO DEPENDENTE NO DOMICÍLIO
}

\author{
RESPONSIBILITIES FOR THE CARE WITH THE \\ DEPENDENT ELDERLY IN THE HOUSEHOLD
}

\section{RESPONSABILIDADES EN EL CUIDADO DE LOS ANCIANOS DEPENDIENTES EN EL HOGAR}

\author{
Karla Ferraz dos Anjos \\ Rita Narriman Silva de Oliveira Boery ${ }^{2}$ \\ Kleverton Bacelar ${ }^{3}$ \\ Darci de Oliveira Santa Rosa ${ }^{4}$
}

Como citar este artigo: Anjos KF, Boery RNSO, Bacelar K, Santa Rosa DO. Responsabilidades pelo cuidado do idoso dependente no domicílio. Rev baiana enferm. 2020;34:e34893.

\begin{abstract}
Objetivos: apreender o significado da palavra responsabilidade para enfermeiros, Agentes Comunitários de Saúde e cuidadores familiares de idosos e identificar as responsabilidades desses profissionais e do familiar pelo cuidado do idoso dependente no domicílio. Método: estudo qualitativo, descritivo e exploratório. A produção dos dados ocorreu com base nos instrumentos: escala de Katz, formulário sociodemográfico e roteiro de entrevista semiestruturada, analisada por meio da Configuração Triádica, Humanista-existencial-personalista. Resultados: as responsabilidades dos profissionais no cuidado ao idoso abrangem acolhimento, acompanhamento, orientação e visita domiciliar. Para os cuidadores envolvem zelo, proteção, acompanhamento e gerenciamento das finanças. Conclusão: as responsabilidades variam, a depender do responsável, tendo relação com dar respostas às necessidades do idoso, ter compromisso, assumir consequências pelas ações e favorecer o bem-estar dos envolvidos.
\end{abstract}

Descritores: Idoso. Enfermeiros. Agentes Comunitários de Saúde. Cuidadores.

Objectives: to understand the meaning of the word responsibility for nurses, Community Health Workers and family caregivers of the elderly and identify the responsibilities of those professionals and the family for the care of the dependent elderly in the household. Method: a qualitative, descriptive and exploratory study. Data production occurred based on the following instruments: Katz scale, sociodemographic form and semi-structured interview guide, analyzed through the Triadic Configuration, Humanistic-existential-personalistic. Results: professionals' responsibilities for the care with the elderly include reception, monitoring, mentoring and visits. For the caregivers, they involve zeal, protection, monitoring and management of finances. Conclusion: the responsibilities vary, depending on the responsible person, realting to meeting the needs of the elderly, compromise, assuming the consequences for the actions and promoting the well-being of those involved.

Descriptors: Aged. Nurses. Community Health Workers. Caregivers.

Objetivos: entender el significado de la palabra responsabilidad para enfermeras, agentes comunitarios de salud y cuidadores familiares de ancianos e identificar las responsabilidades de estos profesionales y la familia para el cuidado de los ancianos dependientes en el hogar. Método: estudio cualitativo, exploratorio y descriptivo. Los datos fueron

\footnotetext{
Enfermeira. Doutora em Enfermagem. Professora da Umime Salvador. Salvador, Bahia, Brasil. karla.ferraz@hotmail.com. https://orcid.org/0000-0002-5453-8303. Enfermeira e Obstetra. Doutora em Enfermagem. Professora Titular da Universidade Estadual do Sudoeste da Bahia. Jequié, Bahia, Brasil. https://orcid.org/00000002-7823-9498.

3 Licenciado em Pedagogia. Bacharel em Direito. Doutor em Filosofia. Professor Associado da Universidade Federal da Bahia. Salvador, Bahia, Brasil. https://orcid. org/0000-0003-3643-5201.

${ }^{4}$ Enfermeira. Doutora em Enfermagem. Professora Adjunta da Universidade Federal da Bahia. Salvador, Bahia, Brasil. https://orcid.org/0000-0002-565I-29I6.
} 
producidos con base en los instrumentos: escala de Katz, formulario sociodemográfico y guion de entrevista semiestructurada, analizados mediante la Configuración Triádica, Humanistica-existencial-personalista. Resultados: las responsabilidades de los profesionales en el cuidado de los ancianos incluyen recepción, supervisión, tutoría y visitas. Para los cuidadores, implican el celo, la protección, la vigilancia y la gestión de las finanzas. Conclusión: las responsabilidades varian, dependiendo de la persona responsable, relacionándose con el atendimiento a las necesidades de los ancianos, compromiso, asumir las consecuencias de las acciones y promover el bienestar de los involucrados.

Descriptores: Anciano. Enfermeros. Agentes Comunitarios de Salud. Cuidadores.

\section{Introdução}

A responsabilidade associa-se à condição de a pessoa ser ou não responsável. Para tanto, pressupõe-se que essa pessoa possui consciência dos atos praticados. Essa consciência confere-lhe a obrigação de reparar danos causados ao outro ${ }^{(1)}$.

Neste estudo, a fundamentação da responsabilidade dá-se nas perspectivas jurídica e moral. Isto devido ao fato de os enfermeiros e Agentes Comunitários de Saúde (ACS) assumirem a responsabilidade jurídica, considerando o exercício profissional. A responsabilidade moral, assumida pelos cuidadores, é motivada pelas relações construídas com o idoso dependente que recebe cuidado.

A responsabilidade jurídica tem relação com a exterioridade. Nesta a pessoa é responsável pelas consequências de sua ação diante do outro, na medida em que pode ser chamada para prestar conta de seus atos. A responsabilidade moral relaciona-se às intenções interiores, e é fundamentada na lei moral. Esta, geralmente, ordena comportamentos diante do outro ${ }^{(2)}$. Isso substitui a ideia de dano pela noção de carga confiada. É pelo outro que a pessoa é responsável ${ }^{(3)}$.

A assunção da responsabilidade pelo cuidado dirigido ao idoso tem sido uma demanda frequente entre os enfermeiros, ACS e famílias. Conforme estudo $^{(4)}$, no campo da saúde, lidar com o envelhecimento e suas particularidades é um dos desafios do século XXI.

Nos serviços de saúde, as demandas advindas dos idosos são crescentes e complexas ${ }^{(4)}$ e têm relação com o envelhecimento da população ${ }^{(5)}$, exigindo atenção multiprofissional e interdisciplinar que contemple suas necessidades de saúde ${ }^{(4)}$. Desse modo, os enfermeiros precisam direcionar suas ações às peculiaridades dos idosos ${ }^{(5)}$. Para isso, é indispensável conhecimentos específicos nas áreas de gerontologia e geriatria ${ }^{(4)}$.

Na Atenção Básica à Saúde (ABS), o cuidado do enfermeiro dispensado aos usuários dos serviços, dentre eles os idosos, tem a finalidade de produzir ações de saúde com base em saber específico e articulado com os demais membros da equipe no contexto político e social do setor saúde. Sua atuação exige competências, habilidades e conhecimento técnico-científico nas diversas áreas ${ }^{(6)}$. Os ACS, por residirem na mesma comunidade que os idosos, geralmente conhecem e vivenciam as necessidades dos moradores. Logo, a atuação desse profissional favorece o cuidado e a execução de suas responsabilidades, dentre as quais destaca-se estabelecer o elo entre a comunidade e a equipe de saúde da $\mathrm{ESF}^{(7)}$.

Em relação ao cuidador familiar, este é o principal responsável pelo cuidado dos idosos no domicílio, especialmente quando prolongado, e isso associa-se aos relacionamentos existentes, questões de gênero, proximidade geográfica, valores, normas e expectativas culturais ${ }^{(8)}$. Diante das crescentes demandas do envelhecimento, ele permannecerá sendo esse responsável em situação de dependência do idoso.

Cuidar do idoso dependente, sobretudo por parte da família, ocasiona estresse, especialmente quando ele se encontra em condição de elevado sofrimento, dor crônica ou comprometimento cognitivo. Em contrapartida, essa prática pode 
favorecer relação empática, em que o cuidador coloca-se no lugar do outro, com o propósito de compreender as suas necessidades. Desse modo, espera-se que o cuidador esteja preparado ou disposto a entrar em contato com o outro que se encontra frágil, em sofrimento e dependente de cuidados $^{(9)}$.

Estudo demonstra que os enfermeiros da ESF têm conhecimentos incipientes em cuidados do idoso ${ }^{(5)}$. Assim como a maioria dos $\mathrm{ACS}^{(4)}$ e dos cuidadores, não receberam capacitação e/ou orientações em saúde em cuidados do idoso ${ }^{(10)}$. Essas circunstâncias têm influenciado na atenção integral e na resolutividade das demandas dos idosos, como explicitado na Política Nacional de Atenção Básica (PNAB) ${ }^{(11)}$, e podem comprometer as reponsabilidades para com as ações de promoção e proteção da saúde, prevenção de agravos, diagnóstico, tratamento, reabilitação, redução de danos e manutenção da saúde.

Diante desse contexto, estudos com essa abordagem justificam-se, por reduzir lacunas na produção científica, além de evidenciarem incipiência de conhecimentos de enfermeiros, ACS e cuidadores familiares em relação ao cuidado do idoso, conforme particularidades desse segmento populacional. Isso pode, de alguma forma, influenciar nas responsabilidades assumidas por essas pessoas. Estudos evidenciam a necessidade de ampliação de seus conhecimentos, capacitações e/ou orientações na perspectiva geriátrica e gerontológica, para execução de cuidados específicos $^{(4-5,12-13)}$, que podem ocorrer com base em práticas educativas em saúde (PES). O enfermeiro pode ser um dos responsáveis para sanar esse déficit.

Nesse sentido, este estudo torna-se relevante diante da possibilidade de contribuir com a identificação das responsabilidades de enfermeiros, ACS e cuidadores junto aos idosos, fomentar novas investigações e subsidiar o planejamento do cuidado a esse segmento populacional.

Este estudo tem por objetivo apreender o significado da palavra responsabilidade para enfermeiros, Agentes Comunitários de Saúde e cuidadores familiares de idosos e identificar as responsabilidades desses profissionais e do familiar pelo cuidado do idoso dependente no domićlio.

\section{Método}

Estudo qualitativo, descritivo e exploratório. Os participantes foram enfermeiros, ACS e cuidadores familiares de idosos, do sexo feminino e masculino, com idade igual ou superior a 18 anos, vinculados às duas ESF da área urbana do município de Manoel Vitorino, localizado no interior do estado da Bahia. A população de Manoel Vitorino (censo 2010) é composta de 14.387 indivíduos. Na área urbana, existem 7.359 pessoas. Destas, 871 são idosas. Este território é composto, predominantemente, por pessoas com baixo poder aquisitivo ${ }^{(14)}$.

Neste estudo, considerou-se família pessoas com vínculos de parentesco, dependência doméstica ou normas de convivência ${ }^{(15)}$; e cuidador familiar, a pessoa da família que auxilia ou desenvolve as atividades cotidianas pelos idosos dependentes.

Este estudo está vinculado à Tese de Doutorado "Responsabilidades pelo Cuidado do Idoso Dependente e Influência de Práticas Educativas em Saúde", defendida junto ao Programa de Pós-Graduação em Enfermagem da Universidade Federal da Bahia em 2018, a qual foi desenvolvida em três etapas distintas, porém interligadas. Para este estudo, utilizaram-se os dados produzidos na primeira etapa: identificação das responsabilidades de enfermeiros, ACS e cuidadores pelo cuidado do idoso dependente (diagnóstico situacional).

A produção dos dados, feita pela pesquisadora e uma enfermeira capacitada para aplicação dos instrumentos, ocorreu na ESF e no domicílio do idoso e/ou de sua família no referido município, no período de fevereiro a março de 2016.

Foram critérios de inclusão adotados para os enfermeiros e ACS: atuar na ESF e ter idade superior a 18 anos; e de exclusão, os profissionais que estavam em férias, licença ou afastados. Para a inclusão dos cuidadores considerou-se: familiar de idoso que apresentasse dependência funcional, conforme a escala de Katz; coabitasse 
no mesmo domicílio que o idoso; tivesse idade igual ou superior a 18 anos; fosse o cuidador principal; cadastrado em ESF; estivesse cuidando do idoso há, no mínimo, seis meses. Como critério de exclusão, as pessoas que, após três visitas em dias e horários distintos e agendados, não fossem encontradas.

Para seleção do cuidador e, consequentemente, dos domicílios, houve apoio dos ACS. Para tanto, foi solicitado a cada ACS que acompanhasse a pesquisadora em até três domicílios nos quais havia idosos considerados por eles como dependentes funcionais. Esse número de domicílios teve o propósito de abranger as duas áreas das ESF e todos os ACS participantes da pesquisa. A escolha dos domicílios sucedeu-se dessa forma, por compreender-se que esses profissionais conheciam os idosos e seus cuidadores familiares, e poderiam apresentar as pesquisadoras às famílias. Considerou-se este momento necessário para favorecer a aproximação, confiança e segurança deles em participar da pesquisa.

Na sequência, foram incluídas as pessoas que se autodeclarassem responsáveis principais pelo cuidado ao idoso. Foram realizadas 26 visitas domiciliares. Destas, 7 domicílios foram excluídos, devido aos idosos serem independentes funcionais e terem cuidadores formais ou que não eram da família. Não houve recusa de participação.

Realizaram-se entrevistas semiestruturadas com os participantes apoiadas nos instrumentos: escala de Independência em Atividades Básicas da Vida Diária (ABVD) - Escala de Katz -, questionário sociodemográfico e formulário. Todas as entrevistas foram gravadas, após consentimento dos participantes, como forma de garantir maior fidedignidade no registro e nas transcrições dos depoimentos.

A escala de Katz, adaptada para o português, foi aplicada para avaliar o desempenho dos idosos nas ABVD em seis funções (banho, vestir-se, ir ao banheiro, transferência, continência e alimentação). Seu uso possibilitou a identificação do grau de (in)dependência do idoso, classificando-o como independente em todas as seis funções ou dependente em uma, duas, três, quatro, cinco ou seis funções ${ }^{(16)}$.
A produção dos dados com os enfermeiros e ACS ocorreu em dois momentos (um em grupo e um individual) e com os cuidadores em três (individual). Ressalta-se que, para o primeiro encontro com os profissionais, a pesquisadora agendou uma reunião coletiva prévia com o enfermeiro e os ACS em cada uma das unidades de saúde, para convidá-los a participar da pesquisa.

No primeiro encontro com todos os participantes, com duração média de uma hora, houve a aproximação, o convite para participarem da pesquisa, assinatura do Termo de Consentimento Livre e Esclarecido (TCLE) e o agendamento das demais etapas. A primeira visita no domicílio do idoso ocorreu com a presença dos ACS.

No segundo encontro com os profissionais, ocorreu a entrevista semiestruturada com os enfermeiros, por meio de formulário semiestruturado. Os ACS responderam a um questionário semiestruturado autoaplicado. Para ambos os participantes, os instrumentos continham 12 perguntas referentes às questões sociodemográficas e responsabilidades pelo cuidado do idoso.

Com os cuidadores, no segundo encontro, ocorreu a aplicação da escala de Katz e do questionário sociodemográfico (com características dos cuidadores e dos idosos dependentes). Ressalta-se que as respostas aos questionamentos da escala de Katz, mesmo sendo utilizada para avaliar o grau de (in)dependência do idoso, foram prestadas pelo cuidador familiar. Esse encontro durou, em média, 40 minutos para cada participante.

O terceiro encontro aconteceu com os cuidadores. A entrevista foi guiada por um roteiro sobre responsabilidades pelo cuidado do idoso. Alguns tiveram dúvidas para descrever o significado da palavra responsabilidade, sendo repetido o questionamento e solicitado que respondessem, conforme o seu entendimento. Após as entrevistas, foram apresentados os resultados da escala de Katz para os cuidadores, com o propósito de informá-los sobre o grau de dependência do idoso que cuidavam. Este encontro variou entre 15 e 40 minutos.

Para cada participante havia um instrumento semiestruturado específico, no qual constavam características sociodemográficas, 
questionamentos sobre tempo de atuação e de cuidado, vínculo familiar, presença de doença, apoio social, formação, orientação ou informação sobre cuidados dos idosos.

$\mathrm{Na}$ entrevista, todos os participantes do estudo foram indagados acerca das seguintes questões: Qual o significado da palavra responsabilidade para você? Apresente-me, pelo menos, três situações de responsabilidade. Que responsabilidade é assumida por você no cuidado do idoso dependente?

Os dados individuais produzidos foram transcritos na íntegra e organizados no programa Microsoft Excel 2010 para leitura, compreensão e apresentação dos resultados. A identidade dos participantes foi preservada, com sigilo garantido das respostas. Para resguardar o anonimato dos participantes, os depoimentos foram identificados com pseudônimo, utilizando-se as letras "E" (enfermeiro), A (ACS) e C (cuidador) seguidas do número indicativo da ordem de realização das entrevistas (E1, A1, C1).

Os depoimentos resultantes das entrevistas foram analisados com base na Configuração Triádica, Humanista-existencial-personalista. Esta análise fundamenta-se em seis passos: leitura atenta do conteúdo expresso, de forma a apreender o seu significado dentro da estrutura global, de maneira sistematizada, após sua organização, com uso de códigos para resguardar o anonimato dos participantes; releitura do texto, com vista à identificação das locuções de efeito, com base na exploração detalhada. Neste passo, a pesquisadora obteve maior aproximação com o conteúdo manifesto, o que contribuiu para a identificação das locuções de efeitos e elaboração dos significados dentro da estrutura global ${ }^{(17)}$; identificação e classificação dos aspectos que apresentavam convergências de conteúdo, com análise global dos depoimentos, para identificar os significados de cada unidade; agrupamento das locuções de efeito, com uso de realce de texto e cor de fonte, para os significados que convergiram em três subcategorias e duas categorias empíricas; apresentação dos agrupamentos, de forma descritiva. Neste passo, houve a triangulação dos dados dos participantes na categoria "conceito de responsabilidade"; e, por fim, análise compreensiva dos dados significativos dos agrupamentos que compõem os resultados deste estudo, com o intuito de expor a ideia principal ${ }^{(17)}$.

Estudo aprovado pelo Comitê de Ética em Pesquisa (CEP) da Escola de Enfermagem da Universidade Federal da Bahia, campus de Salvador, Bahia, considerando as exigências da Resolução n. 466/2012, do Conselho Nacional de Saúde (CNS), do Ministério da Saúde (MS), conforme Parecer n. 1.388.138.

\section{Resultados}

Dois enfermeiros participantes do estudo eram do sexo feminino, tinham idade de 28 e 30 anos, raça/cor branca e parda; casado e solteiro, um com três anos e o outro com seis meses de atuação na ESF do município; um tinha especialização em saúde coletiva.

Com relação aos 10 ACS que compuseram a amostra, todos eram do sexo feminino, com idade mínima de 26 e máxima de 62 anos, 9 autodeclararam-se pardos e 1 branco, 8 eram casados, 7 tinham segundo grau completo; 2, superior completo; e 1, superior incompleto. Entre eles, 5 tinham 17 anos de atuação profissional; 3, 12 anos; e 2, 5 anos.

Os enfermeiros e os ACS informaram não ter recebido capacitação específica na área de gerontologia para prestar cuidados e desenvolver visitas domiciliares aos idosos, em particular os dependentes.

Referente aos 19 cuidadores de idosos entrevistados, 17 eram do sexo feminino, tinham idade entre 33 e 73 anos, 13 autodeclararam-se pardos e 3 brancos; 3 eram analfabetos, 5 tinham ensino fundamental incompleto, 4 ensino fundamental completo e 7 ensino médio incompleto; 10 encontravam-se casados ou em união estável; 14 eram católicos e 5 evangélicos; 17 relataram doenças e faziam uso de medicações diárias. Com relação ao parentesco com o idoso, 10 eram filhas e 2 eram filhos; 4, esposas; 1, irmã; 1 , neta; e 1 , nora.

Entre os cuidadores, 4 cuidavam em tempo inferior a 2 anos, 8 entre 2 e 5 anos, 4 entre 7 e 10 anos, e 3 entre 14 e 22 anos; 14 cuidavam em horário integral. 
Ao considerar o salário mínimo de $\mathrm{R} \$ 880,00$ reais (para o ano de 2016), entre os participantes, 6 recebiam esta quantia (aposentadoria, pensão ou outro benefício social), 3 recebiam até 400 reais (trabalho informal e/ou bolsa família) e 10 não tinham renda mensal individual. Tratando-se da ocupação, 18 cuidadores não exerciam atividade remunerada externa ao domicilio, 1 exercia parcialmente, 14 referiram ter exercido trabalho renumerado anterior à assunção do cuidado do idoso dependente em domicílio.

Quanto ao apoio social, 14 cuidadores informaram receber ajuda de parentes (irmã, filha, mãe, sobrinha, cunhada e nora) e vizinho no cuidado do idoso. Os 19 cuidadores declararam nunca ter participado de curso e/ou grupo de apoio na perspectiva do envelhecimento. Destes, 17 informaram que os profissionais da ESF não forneceram orientações sobre como cuidar do idoso dependente no domicílio e esclareceram que as receberam do enfermeiro, ACS e/ou médico.

A análise dos dados coletados nas entrevistas possibilitou o surgimento de duas categorias e três subcategorias empíricas.

\section{Categoria I- Conceito de responsabilidade}

A responsabilidade foi conceituada por enfermeiros, ACS e cuidadores como dar respostas às atividades, assumir consequências de suas ações e favorecer o bem-estar das pessoas envolvidas. Para isso, requeria pensar antes de agir, ter dedicação e compromisso.

É você ser incumbido de alguns afazeres. Dar conta do que foi estipulado no prazo, com eficiência e eficácia, sempre objetivando o bem-estar das pessoas envolvidas (A6). É tomar conta e dar conta (C6). É ter compromisso em tudo o que fazemos (A3). É cumprir com o que lhe foi concedido e sempre levando em consideração sua capacidade (A2). Se garantir no que você faz (C18). Ser responsável (E2, A1, C4), por qualquer dano que venha acontecer (E2). É pensar muito antes de agir, para não cometer alguma coisa. Não errar, para não ter uma consequência negativa (C11). Responsabilidade tem muito a ver com dedicação (E1).

\section{Categoria II - Responsabilidades pelo cuidado do idoso dependente}

Nesta categoria, emergiram três subcategorias empíricas, que descreveram as responsabilidades dos enfermeiros, ACS e cuidadores no cuidado do idoso dependente.

\section{Subcategoria I - Responsabilidades dos enfermeiros}

As responsabilidades dos enfermeiros no cuidado dos idosos foram expressas como parte da atenção multiprofissional e para dar resolutividade às demandas dessas pessoas. Esses profissionais realizavam encaminhamentos para outros serviços, quando não conseguiam resolver o problema de saúde na ESF.

\footnotetext{
Minha responsabilidade com ele [idoso] é prestar um cuidado multidisciplinar, que não é só eu quem tem que ir lá [no domicílio], já que ela não pode vir até aqui [ESF]. Até porque é um direito dela, o direito à saúde e um dever meu, dar a resolutividade. Muitas vezes, a gente não tem ferramentas suficientes e tem que correr atrás. Eu preciso resolver o problema delas e, se eu não puder resolver, eu tenho que encaminhá-la para um lugar onde ela possa resolver o mais rápido possivel. (E1).
}

Acrescidas a essas, os enfermeiros descreveram ações de acolhimento, respeito às singularidades de cada pessoa, observação do cuidado e do ambiente em que os idosos viviam, acompanhamento, orientação e visita domiciliar.

\begin{abstract}
Acolhimento (E1,2), respeitar essa pessoa [idoso] com tudo que ela traz, com a história (E1). Estar observando os cuidados. Se a paciente está sendo bem tratada, se tem carinho, se tem amor. Se a diabetes e a pressão estão controladas ou não. Está vendo se a medicação está correta, fazendo bem ou não, fazendo efeito. Se o ambiente está limpo e agradável (E2). Está acompanhando [o idoso] (E1) e orientando o cuidador, quanto à medicação e à alimentação (E2).
\end{abstract}

\section{Subcategoria II - Responsabilidades dos ACS}

Os ACS descreveram suas responsabilidades pelo cuidado do idoso na equipe multiprofissional, dentre as quais visitas domiciliares que realizavam sozinhos, com o fito de identificar as condições de saúde do idoso, manter a equipe informada acerca de situações observadas no domicílio e atentar às demandas das famílias que também tinham problemas de saúde. Ademais, realizavam visitas programadas e conjuntas com outros profissionais da equipe da ESF.

Fazer visitas domiciliares (A3). Marcar visitas (A1) acompanhada de técnico de enfermagem, enfermeiro (A4) $e$ médico (A3), as vezes que for preciso (A8). Ser agente de fiscalização (A6) [para] manter o posto sempre informado da situação da família (A7), para averiguar o estado de 
saúde do idoso e como estão sendo cuidados (A4). Não podemos nos esquecer da família que ali está e que também carrega uma série de problemas, tanto na área da saúde física como psicológica. Afinal de contas, somos responsáveis por toda a familia e não só pelo idoso (A2)

Também foram descritas pelos ACS intervenções junto às famílias, quando necessárias, como encaminhamento aos serviços de saúde, orientação quanto à higiene e à medicação, informações sobre os programas ofertados na ESF, escuta e apoio ao idoso e à sua família.

\begin{abstract}
Intervir quando se fizer necessário (A6). Encaminhar (A1) os familiares (A8) aos serviços de saúde (A1). Orientar $(\mathrm{A} 5,7,8,10)$ a família a ter responsabilidade (A5), principalmente os cuidadores (A8) em relação aos programas que são oferecidos na ESF(A1), a bigiene pessoal e o ambiente onde moram, aos cuidados que devem ter (A3) e a tomar a medicação em borário correto (A5). Estar disponível a ouvir (A8). Ajudar quando precisa (A7). Se ele [idoso] não tiver alguém da família que possa cuidá-lo, procurar alguém capacitado, quando for possível, para cuidar (A8)
\end{abstract}

\section{Subcategoria III - Responsabilidades dos cuidadores}

O zelo foi expresso como fundamento das responsabilidades dos cuidadores, ao descreverem as ações desenvolvidas diariamente no cuidado do idoso no domić́lio. Consistia em tomar conta, cuidar da alimentação, ingestão hídrica, medicação e higiene pessoal e do ambiente. Foi mencionado o uso do celular como recurso, para auxílio no planejamento do cuidado.

\begin{abstract}
É cuidar bem (C10). Zelar até a hora que Deus quiser (C7). É zelar na comida, na bebida (C6). Qualquer coisa é eu que tenho que tomar conta $(\mathrm{C} 1,2,5,7,16)$. Dar comida e remédio na hora certa (C1,7,14). Já tem no celular, para a gente não perder o horário, deixo tudo gravado (C1). Dou o banho (C1,7,12,13,16,17,18), o zelo na cama, troco a fralda. A cama arrumada e limpinha. Da parte da casa, eu que faço as coisas (C5,6). Escovo os dentes, faço a barba (C14,16), visto a roupa, cuido do pé, limpo o ouvido (C16), corto o cabelo (C14). Cuido das roupas, do lugar que ela fica, sempre limpo (C5).
\end{abstract}

Os cuidadores familiares têm se responsabilizado também por locomoção do idoso externo e interno ao domicílio, mudanças de decúbito, apoio, companhia com o sono e prevenção de quedas.

Locomovo ele [idoso], que às vezes ela quer ir lá no fundo do quintal (C11), andar na casa (C13) ou ir em algum lugar $(\mathrm{C} 8,11)$. Não deixo ela só $(\mathrm{C} 5,7,8,9,16)$. Ponbo ela para dormir (C6,10). Durmo bem perto e fico (C1) olhando (C10), atenta, porque ela pode cair da cama e se machucar $(\mathrm{C} 8,16)$. Viro ela de noite e levanto para dar uma olhada, para ver como está(C6).

Somam-se a isso, as demandas dos idosos, como as de marcação de consultas e exames, atenção, carinho, realização de compras, gerenciamento das finanças, acompanhamento, estar junto e atento.

Toda bora que precisar de um exame, de uma palavra, de um abraço, o que tiver de resolver, eu tenho que estar junto [idoso] (C17). Faço as compras (C5,6,13), pego o dinbeiro dela, compro as coisas, guardo, para na bora da precisão (C5). Arrumo médico e faço os exames $(\mathrm{C} 5,9,12,17)$. Arrumo um carro para levar e acompanbo (C13,17). Durante o dia, eu estou com aquele cuidado, para alguém não mexer neles. Se sentir alguma coisa, eu estou ali para socorrer (C5). É ter cuidado $(\mathrm{C} 8,13)$.

\section{Discussão}

Os participantes descreveram o significado de responsabilidade e quais assumiam no cuidado ao idoso. O termo refere-se a significados, como o de responder por e ser eficaz ${ }^{(2)}$. Este tem relação com o ser responsável e ter consciência dos atos praticados ${ }^{(1-3)}$. Juridicamente, a pessoa é responsável pelas consequências de sua ação, como danos causados, e o responsável tem a obrigação de reparar o dano que causou e de sofrer a pena ${ }^{(3)}$. Foi nessa perspectiva jurídica que os enfermeiros e ACS descreveram o significado do termo responsabilidades pelo cuidado do idoso dependente e como a pessoa deve assumir suas atribuições inerentes à profissão. Entenderam, portanto, que o profissional precisa responder pelos danos advindos de sua ação.

Quanto à responsabilidade moral, fundamenta-se nas leis morais. É pelo outro que a pessoa é responsável ${ }^{(3)}$. Assim, as pessoas responsáveis agem conforme seus princípios e convicções ${ }^{(18)}$. Os cuidadores familiares atribuíram o conceito de responsabilidade pelo cuidado do idoso em situação de dependência na perspectiva desse sentido moral. Eles consideraram que a pessoa precisa refletir sobre os atos praticados, evitando consequências negativas de sua ação.

Conhecer as responsabilidades jurídica e moral, as específicas dos enfermeiros, ACS e cuidadores familiares é essencial para o planejamento de suas ações. Nesse aspecto, o Ministério 
da Saúde (MS) descreve as atribuições próprias dos membros das equipes de ABS envolvidos na assistência à saúde na ESF. Outras podem constar nas normatizações estabelecidas pelos gestores federal, estadual, municipal ou do Distrito Federal, conforme prioridades definidas pelas respectivas gestões. As atribuições precisam considerar as disposições legais que regulamentam cada profissão ${ }^{(11)}$.

Dentre as atribuições específicas do enfermeiro na ABS, conforme o MS, estão: a atenção à saúde aos indivíduos e às famílias na unidade de saúde, no domicílio e/ou outros espaços comunitários, em todas as fases do desenvolvimento humano; o encaminhamento dos usuários a outros serviços de saúde; e a realização de atividades programadas e de atenção à demanda espontânea ${ }^{(11)}$. Essas atribuições foram mencionadas pelos enfermeiros deste estudo em relação às suas responsabilidades no cuidado ao idoso dependente, contudo há incipiência de conhecimentos sobre suas atribuições privativas na atenção integral desse segmento populacional na ESF.

O código de ética e principais legislações para o exercício da Enfermagem explicitam que o enfermeiro, além de exercer todas as atividades de Enfermagem, algumas são privativas, como a consulta de Enfermagem; participação no planejamento, execução e avaliação da programação de saúde; e organização e direção dos serviços de Enfermagem e de suas atividades técnicas e auxiliares nas empresas prestadoras desses serviços ${ }^{(19)}$.

$\mathrm{Na}$ ABS, estudo demonstra que o enfermeiro atua na gestão e assistência. Suas atividades majoritariamente acontecem dentro dos serviços de saúde, mas também desenvolve práticas na comunidade. Neste serviço ele realiza diferentes ações, como consultas de enfermagem, procedimentos, promoção da saúde, imunização, acolhimento, visita domiciliar, prevenção, práticas educativas, escuta, encaminhamento, reabilitação, atendimentos clínicos, supervisão e treinamento de técnicos de enfermagem e ACS, além de planejamento, supervisão e avaliação dos serviços, educação continuada e permanente ${ }^{(20)}$, o que converge em parte com os resultados deste estudo.

Estudo constata que o enfermeiro da ESF demonstra insegurança no cuidado ao idoso devido ao déficit de conhecimentos sobre os cuidados à saúde dessas pessoas, conforme suas especificidades. Eles não cuidam de forma integral, e o atendimento é restrito àqueles que apresentam doenças e são acompanhados no programa Hiperdia, o que os distancia da promoção da saúde, um dos principais objetivos da ESF. Logo, é reconhecida a necessidade de capacitações desses profissionais nas áreas de gerontologia e geriatria, uma vez que favorecem a aquisição de conhecimentos sobre cuidados e saúde dos idosos ${ }^{(5)}$.

Conforme os resultados deste estudo, os enfermeiros não tinham capacitações específicas em cuidados do idoso. O Código de Ética dos Profissionais de Enfermagem (CEPE), explicita, no capítulo II dos deveres, em seu art. 55, que o enfermeiro necessita "[...] aprimorar os conhecimentos técnico-científicos, éticopolíticos, socioeducativos e culturais, em benefício da pessoa, família e coletividade e do desenvol-

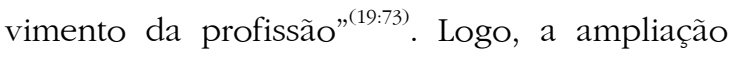
dos conhecimentos dos enfermeiros, na perspectiva do envelhecimento, favorece o planejamento e a implementação de ações direcionadas às particularidades e demandas dos idosos de forma responsável.

Entre as atribuições específicas dos ACS na ABS, de acordo o MS, encontram-se: orientação às famílias quanto aos serviços de saúde disponíveis; realização de atividades programadas e de demanda espontânea; acompanhamento das pessoas sob sua responsabilidade e realização de visitas domiciliares programadas com a equipe de saúde da família, considerando os critérios de risco e vulnerabilidade; desenvolvimento de ações que viabilizem a integração da equipe de saúde da família e da população; desenvolvimento de atividades de promoção da saúde, prevenção de doenças e agravos e de vigilância à saúde; e contato permanente com as famílias, desenvolvendo práticas educativas 
nos domicílios e na comunidade, além de acompanhamento das pessoas com problemas de saúde ${ }^{(11)}$.

Neste estudo, as atribuições descritas pelos ACS estão em consonância com o exposto pelo MS. Todavia, há déficit de conhecimentos desses profissionais, o que pode estar associado à inexistência de capacitação na perspectiva do envelhecimento. A capacitação tem o propósito de contribuir com a prática profissional dos ACS na ESF e no domicílio.

Em estudo desenvolvido com ACS, verificou-se que a maioria não teve capacitação em saúde do idoso para atuar. Os profissionais com maior tempo de trabalho na ESF foram os que as receberam, mas limitou-se ao conhecimento relacionado aos aspectos biológicos do envelhecimento. A capacitação dos ACS e, por conseguinte, a aquisição de conhecimentos específicos na área gerontológica, com o propósito de modificar atitudes, favorece o fortalecimento de sua atuação na equipe de saúde da família e melhora a qualidade do cuidado aos idosos ${ }^{(4)}$. Desse modo, é evidente a necessidade de formação permanente dos ACS, particularmente na área gerontológica, tendo em vista a amplitude de suas responsabilidades na atenção aos idosos. Isso, certamente, influenciará na qualidade do cuidado ofertado.

A complexidade e abrangência do trabalho dos ACS inclui práticas, como visita domiciliar, cadastramento de famílias, promoção da saúde, busca ativa, educação em saúde, organização de grupos terapêuticos, digitação dos cadastros de famílias, vigilância à saúde, atenção aos idosos, encaminhamento para acompanhar pessoas com doenças crônicas e acamados. Destarte, o trabalho do ACS tem como limitantes a deficiência da formação técnica, sobretudo as pessoas com menos de 10 anos de exercício profissional, devido à menor participação em Curso Técnico para ACS, o que tem comprometido sua atuação de forma inconteste. Nesse contexto, a educação permanente e a gestão participativa são potencializadoras do trabalho dos ACS. Desse modo, cabe ao Estado brasileiro garantir a formação necessária e o suporte adequado a esses trabalhadores ${ }^{(21)}$.

Salienta-se que, à medida que a população envelhece e vive mais tempo, há necessidade de os profissionais de saúde atenderem cada vez mais aos idosos e aos seus cuidadores. Diante do comprometimento da autonomia dos idosos, surgem desafios na família, em especial para quem irá assumir a responsabilidade pelos cuidados dessas pessoas. Em consonância com estudo $^{(22)}$, os cuidadores familiares têm assumido esses cuidados fundamentados na responsabilidade moral e não legal. Assim sendo, questiona-se: Os cuidadores estão conscientes de suas responsabilidades e das possíveis implicações legais de suas ações? Os cuidadores estão preparados para cuidar dos idosos? ${ }^{(22)}$.

Estudo demonstra que a responsabilidade filial no cuidado dos idosos, embora seja tradicionalmente enraizada como norma social, tem reduzido ao longo dos anos. As famílias têm enfrentado desafios ao assumir o cuidado dessas pessoas e lidam com esses de formas diferentes. Algumas recebem apoio dos membros familiares, quando necessitam. Esse apoio tem influência da cultura, dos valores e dos recursos pessoais disponíveis $^{(23)}$. Neste estudo, foi visto que a maioria dos cuidadores era filha dos idosos dependentes e recebia apoio da família e/ou de vizinho.

A função do cuidador é acompanhar e auxiliar a pessoa a se cuidar, fazendo por ela somente as atividades que ela não consegue desenvolver sozinha. O MS explicita tarefas que fazem parte da rotina dos cuidadores de idosos em cuidados no domicílio para pessoas acamadas ou com limitações físicas e/ou mentais. Entre essas, algumas estão referidas pelos participantes deste estudo, a exemplo de: escutar, estar atento e ser solidário com a pessoa cuidada; ajudar nos cuidados de higiene e na alimentação; ajudar na locomoção; realizar mudanças de posição na cama e na cadeira, e massagens de conforto; administrar as medicações, conforme a prescrição e a orientação da equipe de saúde ${ }^{(24)}$.

Neste estudo, todos os cuidadores cuidavam de idosos com algum grau de dependência para as ABVD, conforme a escala de Katz, o que 
converge com as atividades demandadas pelos idosos. Todavia, esses cuidados eram desenvolvidos de maneira empírica, o que justifica a necessidade de práticas educativas em saúde com o intuito de conhecerem suas responsabilidades, conforme expõe o Ministério da Saúde.

Para gerenciar o cuidado ao idoso, constatou-se, neste estudo, o uso de celular por cuidadores. A utilização de recursos tecnológicos, como de aplicativos com conexão à internet, pode beneficiar a saúde e o cuidado de idosos, e sua busca tem sido crescente, como demonstra estudo ${ }^{(25)}$. Entre os aplicativos que têm auxiliado no cuidado ao idoso em situação de dependência têm-se o guia para ajudar cuidadores e familiares no cuidado de idosos em casa; my nurse; elderly care; geriatria; biring bome caregivers: family guide; e cuidar de idosos ${ }^{(25)}$. Dessa forma, observa-se carência de conhecimentos dos cuidadores sobre suas tarefas cotidianas no cuidado ao idoso, já que esses aplicativos descrevem, sobretudo, as relacionadas às ABVD. Isso pode associar-se ao déficit de capacitação desses para o cuidado integral no domicílio.

Estudo demonstrou, quase de forma unânime, que os cuidadores não receberam orientações da equipe de saúde para realizar o cuidado ao idoso no domicílio. Foi observada insuficiência de conhecimentos básicos de saúde e de apoio, tal como necessidade de educação em saúde. Todos declararam que gostariam de receber informações, sobretudo relacionadas às doenças, aos medicamentos, às dietas e aos exercícios físicos, com o propósito de melhorar a qualidade dos cuidados prestados a essas pessoas ${ }^{(10)}$. Esses resultados corroboram os deste estudo.

Ao se referir ao cuidado na perspectiva do envelhecimento, estudo aponta que se tem valorizado, sobretudo, o cuidado com o corpo, com ênfase na autonomia e na qualidade de vida dos idosos. Esse contexto biomédico satisfaz a manutenção da vida biológica e desconsidera aspectos essenciais, como o psicológico, afetivo e ético, que envolvem a relação da pessoa cuidada com o cuidador ${ }^{(9)}$. Neste estudo, os responsáveis pelo cuidado do idoso expressaram que suas responsabilidades envolviam questões de natureza biológica, ética, moral, psicológica e social.

Este estudo apresentou como limitações a escolaridade dos cuidadores familiares. Pôde-se observar dificuldades de entendimento do TCLE, de questionamentos feitos durante as entrevistas e de influência de sua participação na transferência de renda do governo, sendo sanadas todas as dúvidas. A esses aspectos acresceram-se interrupções relacionadas às demandas de cuidado do idoso e/ou de solicitações de pessoas conhecidas do cuidador. Sugere-se que outros estudos sejam desenvolvidos para a produção de dados em ambiente diferente do domicílio e que se construam instrumentos com linguagem de fácil acesso a essa população.

\section{Conclusão}

Constatou-se que enfermeiros e ACS viam a perspectiva jurídica da responsabilidade e os cuidadores familiares, os princípios morais. Em ambas as situações, a pessoa responsável deve assumir suas atribuições específicas e responder por elas, objetivando o bem-estar das pessoas envolvidas.

A incipiência de conhecimentos dos profissionais e cuidadores familiares quanto às suas responsabilidades no cuidado aos idosos dependentes pode estar relacionada à inexistência de capacitação e/ou orientações nas áreas geriátrica e gerontológica.

As responsabilidades pelo cuidado do idoso variam, a depender do responsável. Na ESF e/ou no domicílio, os enfermeiros atuam na gestão e assistência e, assim como os ACS, desenvolvem várias atividades, como de vigilância à saúde e cuidado. Como membro da equipe multiprofissional na ABS, esses profissionais descreveram suas responsabilidades. Entre eles, há convergências, como na visita domiciliar, orientação, encaminhamento aos serviços de saúde e vigilância dos cuidados domiciliares. Os cuidadores responsabilizam-se pelo cuidado do idoso, sobretudo nas atividades básicas de vida diária. Para tanto, utilizam o zelo como fundamento. 
Evidenciou-se que as responsabilidades de enfermeiros, ACS e cuidadores familiares condizem com o preconizado e/ou sugerido pelo Ministério da Saúde, assim como harmonizam-se com resultados de outros estudos, embora sejam incipientes e evidenciem a necessidade de ampliação dos conhecimentos direcionados às especificidades dos idosos, notadamente os dependentes funcionais.

Destarte, espera-se que os gestores municipais promovam educação permanente para os enfermeiros e ACS na perspectiva do envelhecimento, e que esses profissionais desenvolvam práticas educativas em saúde voltadas aos cuidadores sobre cuidados dos idosos no domicílio. Essas circunstâncias favorecem o cuidado responsável e de qualidade, conforme as peculiaridades da população idosa.

\section{Colaborações:}

1 - concepção, projeto, análise e interpretação dos dados: Karla Ferraz dos Anjos e Darci de Oliveira Santa Rosa;

2 - redação do artigo e revisão crítica relevante do conteúdo intelectual: Karla Ferraz dos Anjos, Rita Narriman Silva de Oliveira Boery, Kleverton Bacelar e Darci de Oliveira Santa Rosa;

3 - aprovação final da versão a ser publicada: Karla Ferraz dos Anjos, Rita Narriman Silva de Oliveira Boery, Kleverton Bacelar e Darci de Oliveira Santa Rosa.

\section{Referências}

1. Normando P. Um breve estudo sobre o conceito de responsabilidade. Rev Intuitio [Internet]. 2012 [cited 2018 Jan 11];5(2):249-65. Available from: http://revistaseletronicas.pucrs.br/ojs/index.php/ intuitio/article/view/11495

2. Ribeiro LAC. Responsabilidade. In: Barreto VP (coordenador). Dicionário de filosofia do direito. São Leopoldo: Unisinos; 2006. p. 720-1.

3. Ricoeur P. Percurso do reconhecimento. Uma fenomenologia do homem capaz: imputabilidade. Tradução de Campanário NN. São Paulo: Loyola; 2006.

4. Ferreira VM, Ruiz T. Atitudes e conhecimentos de agentes comunitários de saúde e suas relações com idosos. Rev Saúde Pública. 2012;46(5):843-9. DOI:10.1590/S0034-89102012000500011

5. Oliveira MAS, Menezes TMOM. A enfermeira no cuidado ao idoso na estratégia saúde da família: sentidos do vivido. Rev enferm UERJ [Internet]. 2014 [cited 2017 Dec 18];22(4):513-8. Available from: http://www.facenf.uerj.br/v22n4/v22n4a13.pdf

6. Ferreira SRS, Périco LAD, Dias VRFG. A complexidade do trabalho do enfermeiro na Atenção Primária à Saúde. Rev Bras Enferm. 2018;71(suppl1):704-9.DOI:https://doi.org/10.1590/ 0034-7167-2017-0471

7. Peruzzo HE, Bega AG, Lopes APAT, Haddad MCFL, Peres AM, Marcon SS. Os desafios de se trabalhar em equipe na estratégia saúde da família. Esc Anna Nery. 2018;22(4):e20170372. DOI:10.1590/ 2177-9465-ean-2017-0372

8. National Academies of Sciences, Engineering, and Medicine. Schulz R, Eden J, Editors. Families caring for an aging America. Washington (DC): The National Academies Press; 2016. DOI: $10.17226 / 23606$

9. Cherix K, Coelho Junior NE. O cuidado de idosos como um campo intersubjetivo: reflexões éticas. Interface (Botucatu). 2017;21(62):579-88. DOI: $10.1590 / 1807-57622015.0492$

10. Martins JJ, Albuquerque GL, Nascimento ERP, Barra DCC, Souza WGA, Pacheco WNS. Necessidades de educação em saúde dos cuidadores de pessoas idosas no domicílio. Texto \& Contexto - Enferm. 2007;16(2):254-62. DOI:10.1590/S010407072007000200007

11. Brasil. Política Nacional de Atenção Básica. Secretaria de Atenção à Saúde. Departamento de Atenção Básica. Legislação em Saúde [Internet]. Brasília (DF); 2012. Série E. [cited 2019 Nov 20]. Available from: http://189.28.128.100/dab/docs/ publicacoes/geral/pnab.pdf

12. Couto AM, Hell CAI, Lemos IF, Castro EAB. Cuidado domiciliar sob a ótica de idosos dependentes: contribuições para a Enfermagem. Rev Baiana Enferm. 2016;30(4):1-12. DOI: 10.18471/rbe. v30i4.16068

13. Anjos KF, Boery RNSO, Santos VC, Boery EN, Silva JK, Santa Rosa DO. Fatores associados à qualidade de vida de cuidadores familiares de idosos. Cienc enferm. 2018;24(17):1-15. DOI: $10.4067 / \mathrm{s} 0717-95532018000100217$

14. Programa das Nações Unidas para o Desenvolvimento. Atlas do Desenvolvimento Humano no 
Brasil. Brasília (DF); 2020 [cited 2019 Sep 10]. Available from: http://atlasbrasil.org.br/2013/pt/ perfil_m/manoel-vitorino_ba

15. Instituto Brasileiro de Geografia e Estatística. Coordenação de Trabalho e Rendimento. Pesquisa nacional por amostra de domicílios: síntese de indicadores 2015. Rio de Janeiro; 2016 [cited 2015 Jun 19]. Available from: https:// biblioteca.ibge.gov.br/visualizacao/livros/liv98887.pdf

16. Lino VTS, Pereira SEM, Camacho LAB, Ribeiro Filho ST, Buksman S. Adaptação transcultural da Escala de Independência em Atividades da Vida Diária (Escala de Katz). Cad Saude Pública. 2008;24(1):103-12. DOI: 10.1590/S0102311X2008000100010

17. Vietta EP. Configuração triádica, humanista-existencial-personalista: uma abordagem teórica-metodológica de aplicação nas pesquisas de enfermagem psiquiátrica e saúde mental. Rev Latino-am enfermagem. 1995;3(1):31-43. DOI: 10.1590/S0104-11691995000100004

18. Dworkin R. A raposa e o porco-espinho: justiça e valor. Tradução Cipolla MB. São Paulo: Martins Fontes; 2014.

19. Conselho Regional de Enfermagem de São Paulo. Código de Ética e Principais Legislações para o Exercício da Enfermagem. São Paulo; 2018 [cited 2019 Jun 19]. Available from: https://portal. coren-sp.gov.br/wp-content/uploads/2018/11/ Codigo-de-etica.pdf

20. Barbiani R, Nora CRD, Schaefer R. Nursing practices in the primary health care context: a scoping review. Rev Latino-Am Enferm. 2016;24:e2721. DOI: $10.1590 / 1518-8345.0880 .2721$
21. Barreto ICHC, Pessoa VM, Sousa MFA, Nuto SAS, Freitas RWJF, Ribeiro KG, et al. Complexidade e potencialidade do trabalho dos Agentes Comunitários de Saúde no Brasil contemporâneo. Saúde debate. 2018;42(spe1):114-29. DOI: 10.1590/ 0103-11042018s108

22. Wylie LE, Brank EM. Assuming Elder Care Responsibility: Am I a Caregiver? J Emp Legal Studies. 2009 Dec;6(4):899-924. DOI:10.1111/ j.1740-1461.2009.01164.x

23. Ron P. The Relationship between Attachment Styles in Adulthood and Attitudes towards Filial Responsibility: a Comparison between Three Generations of Arabs and Jewish Women. Psychology. 2016 Jan;7(6):741-52. DOI:10.4236/ psych.2016.76077

24. Brasil. Ministério da Saúde. Secretaria de Atenção à Saúde. Secretaria de Gestão do Trabalho e da Educação na Saúde. Guia prático do cuidador. Normas e Manuais Técnicos, Série A. Brasília (DF); 2008 [cited 2019 Jun 19]. Available from: http://bvsms.saude.gov.br/bvs/publicacoes/guia_ pratico_cuidador.pdf

25. Amorim DNP, Sampaio LVP, Carvalho GA, Vilaça KHC. Aplicativos móveis para a saúde e o cuidado de idosos. Rev Eletron Comun Inf Inov Saúde [Internet]. 2018 [cited 2019 Feb 12];12(1):58-71. Available from: https://www.reciis.icict.fiocruz.br/ index.php/reciis/article/view/1365

Recebido: 17 de dezembro de 2019

Aprovado: 17 de fevereiro de 2020

Publicado: 15 de abril de 2020

A Revista Baiana de Enfermagem utiliza a Licença Creative Commons - Atribuição-NãoComercial 4.0 Internacional. https://creativecommons.org/licenses/by-nc/4.0/

Este artigo é de acesso aberto distribuído sob os termos da Licença Creative Commons (CC BY-NC). Esta licença permite que outros remixem, adaptem e criem a partir do seu trabalho para fins não comerciais. Embora os novos trabalhos tenham de lhe atribuir o devido crédito e não possam ser usados para fins comerciais, os usuários não têm de licenciar esses trabalhos derivados sob os mesmos termos. 